\title{
openheart Impact of residence altitude on readmission in patients with heart failure
} Makoto Saito, Manami Yamaoka, Mayuri Ohzawa, Emi Tominaga, Kayo Takahashi,
Toru Morofuji, Takumi Sumimoto, Shinji Inaba

\begin{abstract}
- Additional material is published online only. To view please visit the journal online (http://dx.doi.org/10.1136/ openhrt-2018-000865).
\end{abstract}

To cite: Saito M, Yamaoka M, Ohzawa M, et al. Impact of residence altitude on readmission in patients with heart failure. Open Heart 2018;5:e000865. doi:10.1136/ openhrt-2018-000865

Received 25 May 2018 Revised 20 August 2018 Accepted 22 August 2018
Check for updates

\section{(C) Author(s) (or their} employer(s)) 2018. Re-use permitted under CC BY-NC. No commercial re-use. See rights and permissions. Published by BMJ.

Cardiology, Kitaishikai Hospital, Ozu, Japan

\section{Correspondence to}

Dr Makoto Saito; saito0321jp@ yahoo.co.jp

\section{ABSTRACT}

Objective Mountain districts normally have tougher geographic conditions than plain districts, which might worsen heart failure (HF) conditions in patients. Also, those places frequently are associated with social problems of ageing, underpopulation and fewer medical services, which might cause delay in detection of disease progression and require more admissions. We investigated the association of residence altitude with readmission in patients with $\mathrm{HF}$.

Methods We followed 452 patients with HF to determine all-cause readmissions over a median of 1.1 years. The altitude of patient residences, population, proportion of the elderly and number of hospitals or clinics in a minor administrative district (Cho-Aza district) located at the residences were examined using data from the 2010 census and Google Maps.

Results All-cause readmissions were observed in 269 $(60 \%)$ patients. The altitude of $\geq 200 \mathrm{~m}$ was significantly associated with readmissions ( $\mathrm{HR}, 1.49 ; 95 \% \mathrm{Cl} 1.12$ to $1.96 ; p=0.006$ ) after adjustment for physical and haemodynamic parameters, left ventricular ejection fraction, brain natriuretic peptide and components of the established score for predicting readmission for HF. Altitude was significantly associated with ageing, underpopulation, fewer hospitals or clinics and lower temperature (all $p<0.01$ ), with an increased tendency for readmission during the winter season; however, it was not associated with patient clinical parameters.

Conclusions High altitude residence may be an important predictor for readmission in patients with HF. This relationship may be confounded by unfavourable sociogeographic conditions at higher altitudes.

\section{INTRODUCTION}

Heart failure $(\mathrm{HF})$ is a leading cause of hospital readmission in patients aged $>65$ years. ${ }^{1}$ Readmission rates still are increasing. ${ }^{2}$ This poses significant problems, including prognosis, impaired quality of life and increased costs and resource use. ${ }^{1-4}$ Also, ageing patients with $\mathrm{HF}$ are increasingly common in an ultra-ageing society, and the majority of them are frail and suffer from multiple chronic comorbidities. ${ }^{5-10}$

\section{Key questions}

What is already known about this subject?

- Heart failure (HF) readmissions are a common and serious problem of heterogeneous aetiology.

- Mountain districts normally have tougher geographic conditions than plains districts.

- Those places frequently are associated with ageing, underpopulation and fewer medical services.

What does this study add?

- Residence at high altitudes may be an important risk factor for readmission in patients with HF.

- This relationship may be confounded by unfavourable sociogeographic conditions at higher altitudes.

How might this impact on clinical practice?

- Clinician should recognise the residence of patients with $\mathrm{HF}$ as a risk factor for readmission.

- Policy makers should consider improvement of unfavourable social conditions of mountain districts.

These patients require readmissions due to worsening HF and other comorbidities. ${ }^{2}$

Geographically, Japan is known for its rugged, mountainous terrain; over $70 \%$ of the national land consists of mountains and hills, particularly in the rural areas. Mountain districts normally have steeper slopes, lower temperatures and greater temperature changes than the plains, which might worsen HF conditions in patients. ${ }^{11-13}$ Also, those places frequently are associated with social problems of ageing, underpopulation and fewer medical services, which might cause delay in detection of disease progression and require more admissions.

Many readmissions for $\mathrm{HF}$ are predictable and, therefore, possibly preventable. ${ }^{1} 1415$ Recently, identifying risks in the environment following hospitalisation for HF has been studied for more appropriate prevention of readmission. ${ }^{16}$ On these grounds, it is important for policy makers and clinicians to recognise the sociogeographic and clinical factors causing patients to be at highest risk 
for readmission. ${ }^{17}$ Therefore, we investigated the association of altitude of the residence with readmission and its confounding factors in patients with HF.

\section{METHODS}

\section{Study subjects}

This is a retrospective cohort study. We evaluated patients enrolled from the Kitaishikai Hospital admission database, which consists of all admitted patients and their primary diagnosis code (International Classification of Diseases, 10th revision code (ICD-10)) related to the index admission. From this database, we identified 525 consecutive patients (age range, 30-90 years) admitted to Kitaishikai Hospital in Ozu City, from July 2006 to June 2014, with a primary diagnosis of congestive HF (ICD-10 codes, I500 congestive HF, I501 left ventricular failure, and I509 HF, unspecified). Ozu City is located in Ehime Prefecture on the western coast of Shikoku, in a rural area of Japan. Its population is small (approximately 35000 people). Kitaishikai Hospital is a main hospital in Ozu City to back up general physicians, and most regular patients are usually admitted to this hospital. Furthermore, only Kitaishikai Hospital provides cardiology services in this medical district. Two cardiologists (KT and TM) independently checked each patient's medical record to confirm the diagnosis of HF. Any disagreement was resolved by a third cardiologist (TS). The definition of HF was as a combination of typical signs or symptoms and objective evidence of cardiac dysfunction (chest X-ray and echocardiography) in reference to the previous report. ${ }^{18}$ The following patients were excluded because the reason of admission was not HF $(n=73)$ : coronary artery disease $(n=29)$, followed by hospital transfer at the date of admission $(n=9)$, renal failure $(\mathrm{n}=8)$, workup $(\mathrm{n}=5)$, lung disease $(\mathrm{n}=4)$, arrhythmia $(n=4)$, depression $(n=4)$, dehydration $(n=4)$, cerebrovascular disease $(n=3)$ and cancer $(n=3)$. Finally, 452 patients were enrolled in the study.

\section{Clinical data}

The clinical parameters at discharge (demographic variables, comorbidity and medical history, sociodemographic variables and vital signs) were collected by an investigator blinded to the findings using the medical records. Serum markers and left ventricular ejection fraction acquired closest to discharge were also assessed. B-type natriuretic peptide (BNP) at admission also was collected in addition to the data on BNP at discharge.

The conventional risk score to predict all-cause readmission of a patient with HF according to the study of Krumholz et al was also calculated. ${ }^{19}$ The score assigned points according to four variables $(0$ and 4 indicating the lowest and highest, respectively). One point was added to each variable as follows: any admission during the previous year, history of HF or diabetes mellitus and serum creatinine $>2.5 \mathrm{mg} / \mathrm{dL}$ at discharge. In our study, the history of HF admission before the index admission was applied as 'history of HF'.

\section{Sociogeographic and climate data}

The altitude of patients' residences was determined using Google Maps Elevation API (https://developers.google. $\mathrm{com} / \mathrm{maps} /$ documentation/javascript/elevation). The population and proportion of the elderly ( $\geq 65$ years and $\geq 75$ years) in the minor administrative district (Cho-Aza district) located at the residence were assessed using data from the 2010 census (http://www.stat.go.jp/english/ index.html). Median area of the Cho-Aza district was 3.8 $\mathrm{km}^{2}$ (IQR, 1.6-8.7 km²). Google Maps (https://maps. google.com/) was used to measure the distance from the residence to Kitaishikai Hospital and to determine the number of hospitals or clinics in the Cho-Aza district (dental, paediatrics, obstetrics and gynaecology and ophthalmology clinics were excluded; online supplementary figure 1 . Furthermore, average daily temperature from July 2006 to June 2014 in the major administrative district (Gun-City district) located at the residence was checked using data from the Japan Meteorological Agency (http://www.jma.go.jp/jma/indexe.html).

\section{Outcome}

The primary endpoint included all-cause unplanned readmission after discharge. Only readmission data for Kitaishikai Hospital were analysed considering Kitaishikai Hospital characteristics. Two cardiologists (SI and MS) checked each medical record to confirm readmission. The secondary endpoint included HF-specific readmission assessed by a similar definition of inclusion criteria. Patients were censored at the time of each outcome or at the end of follow-up (31 July 2015).

Since Japan is located in the northern hemisphere, readmission from April to September was defined as readmission in the summer season and from October to March as readmission in the winter season.

\section{Statistical analysis}

Data were missing from $0.8 \%$ of the records, except for $\mathrm{BNP}$ at discharge (11.5\%). Missing BNP at discharge was imputed from propensity score models using parameters without missing data (age, sex, body mass index (BMI), systolic blood pressure, heart rate, BNP at admission, diabetes mellitus, haemoglobin and serum creatinine). Other continuous variables $(<5 \%)$ were imputed using the corresponding mean value.

Continuous data are expressed as mean $\pm \mathrm{SD}$, or as median $((\mathrm{IQR}))$ according to the distributions of the study parameters. Survival analysis was performed using Cox proportional hazard analysis. The simple association of study variables with readmissions was assessed in the univariate analysis. The associations between readmissions and each geographic parameter were evaluated after the adjustment of the following patient clinical parameters: age, sex, BMI, systolic blood pressure, heart rate, left ventricular ejection fraction, haemoglobin, 
BNP at discharge and four components of the Krumholz score. Particularly, the associations between readmissions and residence altitude were assessed by adjusting sociogeographic parameters as well as the patient clinical parameters. Univariate linear regression analyses were used to confirm the associations between altitude and study parameters in the present cohort. For multiple comparisons, a one-way analysis of variance was used, followed by Bonferroni correction. Statistical analysis was performed using the Standard Statistical Software Package (SPSS) software V.20.0, and $\mathrm{p}<0.05$ indicates statistical significance.

\section{RESULTS \\ Patient characteristics}

Table 1 summarises patient baseline clinical and geographic parameters. Median altitude of patient residences was $64 \mathrm{~m}$. Median proportion of the population $\geq 65$ years in the Cho-Aza district located at the residence was $35 \%$. This proportion obviously was higher than the average percentage of the population $\geq 65$ years in Japan in 2010 (23\%). Median number of hospitals or clinics in that district was zero.

\section{Events}

Follow-up data were available for all 452 patients with 269 $(60 \%)$ all-cause readmissions over a median of 1.1 years (IQR 0.3-2.9 years). Of these readmitted patients, only $132(49 \%)$ were readmitted because of worsening HF. The most common reason for readmission other than HF was lung disease (37 events, 14\%), followed by kidney and urinary disease (20 events, $7 \%$ ).

The secondary outcome, HF-specific readmission, was observed in $145(32 \%)$ patients over a median of $2.5 \mathrm{y}$ (IQR 0.9-4.8 years).

\section{Association of residence altitude with readmissions}

Altitude of patient residences (per $25 \mathrm{~m}$ ) was significantly associated with all-cause readmission (HR 1.02; 95\% CI, 1.00 to $1.05 ; \mathrm{p}=0.04$ ) and HF-specific readmission (HR $1.04 ; 95 \%$ CI 1.01 to $1.07 ; \mathrm{p}=0.01$ ).

Table 2 shows associations of geographic and climate parameters with readmissions after adjustment of patient clinical parameters. Residence altitude was associated with both outcomes. Particularly, the associations between altitude $\geq 200 \mathrm{~m}$ and readmissions were significant. Also, all-cause readmission tended to be associated with ageing and underpopulation in the vicinity of the residence.

\section{Factors associated with residence altitude}

Table 3 shows the associations of residence altitude with study parameters. The altitude was significantly associated with remoteness from the hospital, ageing, underpopulation, fewer hospitals or clinics, lower temperature and greater temperature difference in the neighbourhood of the residence. Also, altitude was associated with winter season of readmission (figure 1). However, it was not associated with patient clinical parameters.

\begin{tabular}{|c|c|}
\hline & Overall \\
\hline Variable & $(n=452)$ \\
\hline Age (years) & $81(74-85)$ \\
\hline Male sex, n (\%) & $240(53)$ \\
\hline Body mass index $\left(\mathrm{kg} / \mathrm{m}^{2}\right)$ & $21.9 \pm 4.0$ \\
\hline Systolic blood pressure (mm Hg) & $113(102-126)$ \\
\hline Heart rate (per min) & $66(60-76)$ \\
\hline Admissions in past year, $\mathrm{n}(\%)$ & $115(25)$ \\
\hline First admission due to heart failure & $296(66)$ \\
\hline Diabetes, n (\%) & $124(27)$ \\
\hline Haemoglobin (g/L) & $11.7(10.2-13.0)$ \\
\hline B-type natriuretic peptide at admission $(\mathrm{pg} / \mathrm{mL})$ & $570(308-1121)$ \\
\hline B-type natriuretic peptide at discharge $(\mathrm{pg} / \mathrm{mL})$ & $220(112-423)$ \\
\hline Creatinine (mg/dL) & $1.0(0.8-1.4)$ \\
\hline Creatinine $\geq 2.5, \mathrm{n}(\%)$ & $26(6)$ \\
\hline Left ventricular ejection fraction (\%) & $51(41-62)$ \\
\hline Krumholz score & $1(0-2)$ \\
\hline \multicolumn{2}{|l|}{ Socioeconomic variables } \\
\hline Living alone, $\mathrm{n}(\%)$ & $80(18)$ \\
\hline Low income*, n (\%) & $42(9)$ \\
\hline Number of housemates & $1(1-3)$ \\
\hline \multicolumn{2}{|l|}{ Geographic and climate variables } \\
\hline Altitude of patients' residence $(\mathrm{m})$ & $64(15-188)$ \\
\hline Altitude $\geq 200 \mathrm{~m}$ of patients' residence, $\mathrm{n}(\%)$ & $100(22)$ \\
\hline Distance from patients' residence to hospital† (km) & $16(7-24)$ \\
\hline Population‡ (persons) & $647(284-1863)$ \\
\hline Proportion of the population $\geq 65$ years $\ddagger(\%)$ & $35(28-42)$ \\
\hline Proportion of the population $\geq 75$ years $\ddagger$ (\%) & $20(16-25)$ \\
\hline Number of hospital or clinicsł (\%) & $0(0-2)$ \\
\hline Mean temperature in a day $\left({ }^{\circ} \mathrm{C}\right)$ & $15.7 \pm 0.3$ \\
\hline Maximum daily temperature $\left({ }^{\circ} \mathrm{C}\right)$ & $21.0 \pm 0.9$ \\
\hline Minimum daily temperature $\S\left({ }^{\circ} \mathrm{C}\right)$ & $11.5 \pm 0.8$ \\
\hline Difference of daily temperature $\S\left({ }^{\circ} \mathrm{C}\right)$ & $9.5 \pm 1.5$ \\
\hline
\end{tabular}

Data are expressed as mean $\pm \mathrm{SD}$, median $(\mathrm{IQR})$ or number (percentage).

*Patients who were certified as a resident tax exemption. †Kitaishikai Hospital.

¥ln the minor administrative district (Cho-Aza district) located at patients' residence.

$\S$ Average temperature in a day from July 2006 to June 2014 in the major administrative district (Gun-City district) located at patients' residence.

Accordingly, the associations between the residence altitude and readmission were reconfirmed by adjusting using patient clinical parameters (age, sex, BNP at discharge, hospitalisation in the prior year, history of $\mathrm{HF}$ admission, diabetes and creatinine $>2.5 \mathrm{mg} / \mathrm{dL}$ ) and sociogeographic variables (distance from patients' residence to hospital, population, proportion of the population $\geq 75$ years, number of hospital or clinics and mean 
Table 2 Associations of geographic and climate parameters with outcomes after adjustment of patient clinical parameters

\begin{tabular}{|c|c|c|}
\hline Variable & $\begin{array}{l}\text { All-cause readmission } \\
\text { HR }(95 \% \mathrm{Cl}), \mathrm{p} \text { values }\end{array}$ & $\begin{array}{l}\text { HF-specific readmission } \\
\text { HR }(95 \% \mathrm{Cl}) \text {, p values }\end{array}$ \\
\hline Altitude of patients' residence (per $25 \mathrm{~m}$ ) & 1.03 (1.00 to 1.05$), p=0.02$ & 1.04 (1.01 to 1.07$), p=0.02$ \\
\hline Altitude of patients' residence $\geq 200 \mathrm{~m}$ & 1.49 (1.12 to 1.96$), p=0.006$ & 1.97 (1.37 to 2.83 ), $p<0.001$ \\
\hline $\begin{array}{l}\text { Distance from patients' residence to hospital* (per } \\
1 \mathrm{~km} \text { ) }\end{array}$ & 0.99 (0.98 to 1.00$), p=0.23$ & 1.00 (0.98 to 1.01$), p=0.76$ \\
\hline Population† (per 100 persons) & 0.98 (0.97 to 1.00$), p=0.009$ & 0.99 (0.97 to 1.00$), p=0.11$ \\
\hline Proportion of the population $\geq 75$ years $†$ (per $1 \%$ ) & 1.02 (1.00 to 1.03$), p=0.04$ & 1.01 (0.99 to 1.04$), p=0.45$ \\
\hline Number of hospital or clinics† & 0.98 (0.91 to 1.05$), p=0.54$ & 0.98 (0.90 to 1.08$), p=0.69$ \\
\hline Mean temperature in a day $\ddagger\left(\right.$ per $\left.1^{\circ} \mathrm{C}\right)$ & 0.97 (0.64 to 1.46$), p=0.87$ & 0.84 (0.48 to 1.47$), p=0.53$ \\
\hline Difference of temperature in a day $\ddagger$ (per $\left.1^{\circ} \mathrm{C}\right)$ & 1.01 (0.93 to 1.10$), p=0.74$ & 0.94 (0.85 to 1.04$), p=0.23$ \\
\hline
\end{tabular}

All associations of study variables with outcomes were adjusted by age, sex, BMI, systolic blood pressure, heart rate, left ventricular ejection fraction, haemoglobin, BNP at discharge, hospitalisation in the prior year, history of HF admission, diabetes and creatinine $>2.5 \mathrm{mg} / \mathrm{dL}$.

$\mathrm{P}<0.008$, significant based on Bonferroni correction.

*Kitaishikai Hospital.

†In the minor administrative district (Cho-Aza district) located at patients' residence.

$\ddagger$ Average daily temperature from July 2006 to June 2014 in the major administrative district (Gun-City district) located at patients' residence. BMI, body mass index;BNP, B-type natriureticpeptide;HF, heart failure.

Table 3 Associations of residence altitude (per $25 \mathrm{~m}$ ) with study parameters

\begin{tabular}{|c|c|c|c|c|}
\hline Variables & B & $95 \% \mathrm{Cl}$ & Standardised $B$ & $P$ values \\
\hline Age (per 1 year) & 0.03 & -0.02 to 0.07 & 0.05 & 0.30 \\
\hline Male sex & -0.43 & -1.33 to 0.47 & -0.04 & 0.35 \\
\hline Haemoglobin (per $1 \mathrm{~g} / \mathrm{L}$ ) & 0.05 & -0.18 to 0.28 & 0.02 & 0.66 \\
\hline $\begin{array}{l}\text { BNP at discharge (per } 100 \\
\mathrm{pg} / \mathrm{mL} \text { ) }\end{array}$ & 0.01 & -0.12 to 0.15 & 0.01 & 0.87 \\
\hline $\begin{array}{l}\text { Left ventricular ejection } \\
\text { fraction (per } 5 \% \text { ) }\end{array}$ & 0.05 & -0.11 to 0.21 & 0.03 & 0.51 \\
\hline Krumholz score & 0.02 & -0.49 to 0.53 & 0.01 & 0.94 \\
\hline Living alone & -0.50 & -1.58 to 0.57 & -0.04 & 0.36 \\
\hline Low income* & 0.32 & -0.75 to 1.39 & 0.03 & 0.55 \\
\hline $\begin{array}{l}\text { Number of housemates (per } \\
\text { one person) }\end{array}$ & -0.08 & -0.37 to 0.21 & -0.03 & 0.59 \\
\hline $\begin{array}{l}\text { Distance from patients' } \\
\text { residence to hospital† (per } \\
10 \mathrm{~km} \text { ) }\end{array}$ & 1.31 & 0.94 to 1.67 & 0.32 & $<0.01$ \\
\hline Population $\ddagger($ per 100 persons) & -0.21 & -0.24 to -0.17 & -0.45 & $<0.01$ \\
\hline $\begin{array}{l}\text { Proportion of the population } \\
\geq 75 \text { years } \ddagger \text { (per } 1 \% \text { ) }\end{array}$ & 0.34 & 0.29 to 0.39 & 0.54 & $<0.01$ \\
\hline Number of hospital or clinicsł & -0.99 & -1.21 to -0.77 & -0.39 & $<0.01$ \\
\hline $\begin{array}{l}\text { Mean temperature in a day§ } \\
\left(\text { per } 1^{\circ} \mathrm{C}\right)\end{array}$ & -5.05 & -6.47 to -3.63 & -0.31 & $<0.01$ \\
\hline $\begin{array}{l}\text { Difference of temperature in } \\
\left.\text { a day§ (per } 1^{\circ} \mathrm{C}\right)\end{array}$ & 0.58 & 0.28 to 0.88 & 0.18 & $<0.01$ \\
\hline
\end{tabular}

*Patients who were certified as a resident tax exemption.

†Kitaishikai Hospital.

¥ln the minor administrative district (Cho-Aza district) located at patients' residence.

§Average temperature in a day from July 2006 to June 2014 in the major administrative district (Gun-City district) located at patients' residence.

BNP, B-type natriuretic peptide. 

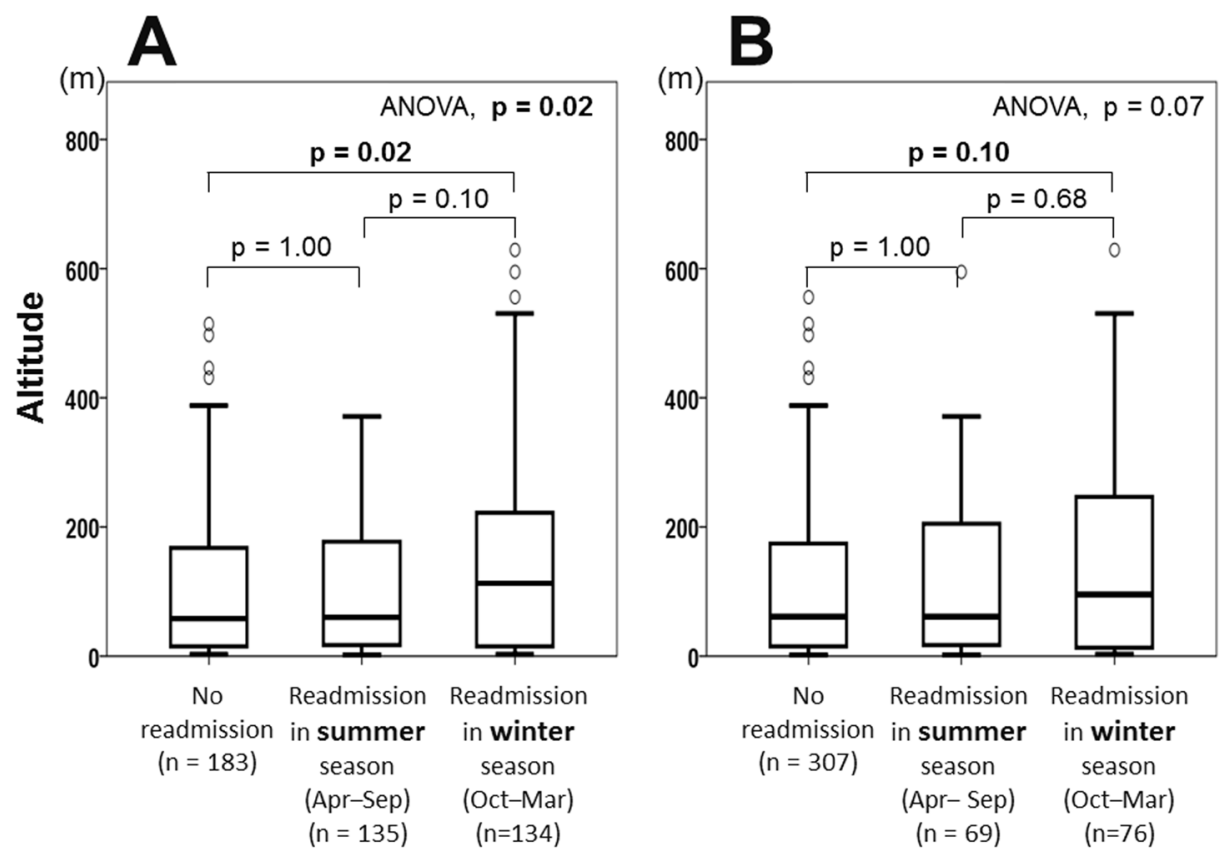

Figure 1 Association of residence altitude and season of readmission ((A): all-cause readmission; (B): heart failure-specific readmission). ANOVA, analysis of variance.

temperature in a day). As a result, HF-specific readmission was still strongly associated with residence altitude (per $25 \mathrm{~m}$ ) (HR 1.04; 95\% CI 1.00 to 1.09; $\mathrm{p}=0.03$ ), but the association between all-cause readmission with the altitude was further weakened (HR 1.02; 95\% CI 0.99 to $1.05 ; \mathrm{p}=0.19)$.

\section{DISCUSSION}

We demonstrated that residence altitude, particularly HF-specific readmission, could be a risk factor for readmission in patients with HF. Also, the relationship might be confounded by the unfavourable sociogeographic conditions at higher altitudes.

\section{Mechanism of the association between high altitude and readmissions}

Nearly $70 \%$ of Japan is covered with mountains, more in rural areas, that have relatively steep slopes, low temperatures and large temperature changes even though they are not so high above sea level. These geographical disadvantages are frequently hard, particularly for elderly people and those with HF. ${ }^{11-13}$ In addition, the mountain districts have social disadvantages, such as ageing, underpopulation and limited healthcare services, which might lead to delay in detection of worsening conditions and finally admission.

In fact, in our study, high altitude was significantly associated with unfavourable social and climate conditions as expected. Also, the association between all-cause readmission and residence altitude after adjusting for patient clinical conditions was further weakened after adding the adjustment of sociogeographic parameters. These results could suggest that unfavourable sociogeographic conditions represented by residence altitude could be an important risk factor for readmission in patients with HF.

The cause of strong association between residence altitude and HF-specific readmission after adjustment with clinical and sociogeographic parameters was unknown but might be influenced by unmeasured confounder such as the steepness of slope.

Interestingly, the second and third most frequent causes of all-cause readmission were lung and renal diseases. These diseases could easily worsen during a relatively short period, particularly in elderly people. Therefore, their early detection is important. Possibly, the results of our study might partly explain the delay in detection at a high altitude area.

Several articles have reported the beneficial effects of high altitude exposure for improving anaemia and lung and heart function in elderly patients. ${ }^{20-22}$ However, this type of high altitude generally is considered $>2500$ $\mathrm{m}$ above sea level. ${ }^{21}$ In our study, left ventricular ejection fraction and haemoglobin were not associated with altitude. Because the present target places were not so high, altitude might be more associated with unfavourable sociogeographic condition rather than its beneficial effects.

\section{Associations between other sociogeographic and climate parameters and readmissions}

In the present study, remoteness from the hospital, fewer healthcare services and the parameters regarding 
temperature were not significantly associated with readmissions. The distance from the residence to the primary hospital was relatively close compared with distances noted in Western countries. Also, the study location included relatively warm and comfortable places, even at high altitudes. These reasons might explain the difference in our results from those of prior studies. ${ }^{13} 17$ However, several articles have reported that remoteness was not necessarily associated with adverse outcomes, which was compatible with our results. ${ }^{2324}$

\section{Clinical implication}

Our study demonstrated that high altitude places in rural Japan were sociogeographically deprived places, which could worsen the conditions in patients with HF and cause readmissions. This information would be important especially for policy makers and hospital staff.

Because medical resources are limited, probably one solution would be to expand the monitoring system for patients using phones and information and communication technology. ${ }^{25}$ Obviously, regular home visits by doctors and medical staff would be efficient, but preparation of financial support, such as long-term care insurance, would be crucial to take this service fairly. ${ }^{27}$ Furthermore, enlightenment of residents regarding the importance of constructing the cooperation system in the neighbourhood would be effective.

\section{Study limitations}

Our data should be interpreted according to the study's limitations. First, geographic bias may exist, and generalisation might be difficult because this is a single-centre study. However, high altitude places in our study represent poor sociogeographic areas. Therefore, our results may be reproduced in a location with a similar environment. Nonetheless, a much larger multicentre study is essential to confirm our results. Second, this retrospective analysis may have been biased because of potential unmeasured confounders such as steepness of slope, although we tried to correct the confounders regarding altitude. Finally, although most regular patients should be admitted to Kitaishikai Hospital, some might present to other hospitals. However, the possibility would be small considering the circumstances of Kitaishikai Hospital.

\section{CONCLUSIONS}

We demonstrated that altitude of the residence could be a risk factor for readmission, particularly HF-specific readmission, in patients with HF in rural Japan. Additionally, this relationship might be confounded by the unfavourable sociogeographic conditions at higher altitudes. However, geographic bias may exist; therefore, a larger multicentre study should be warranted to confirm our results.

Acknowledgements The authors gratefully acknowledge the assistance of Masaru Morino in compiling the outcome data.
Contributors MS designed the protocol and extracted and analysed the data, conducted the statistical analysis and drafted and revised the draft paper. MY, MO, $\mathrm{ET}$, TM and KT extracted data and cleaned the data. SI contributed to conception and extracted data and revised the draft paper. TS revised the draft paper. All authors had full access to the data and are guarantors for the study.

Funding This research did not receive any specific grant from funding agencies in the public, commercial or not-for-profit sectors.

Competing interests None declared.

Patient consent Not required.

Ethics approval The study was approved by the ethics committee of Ehime University Graduate School of Medicine (\#1512001).

Provenance and peer review Not commissioned; internally peer reviewed.

Data statement No additional data are available.

Open access This is an open access article distributed in accordance with the Creative Commons Attribution Non Commercial (CC BY-NC 4.0) license, which permits others to distribute, remix, adapt, build upon this work non-commercially, and license their derivative works on different terms, provided the original work is properly cited, appropriate credit is given, any changes made indicated, and the use is non-commercial. See: http://creativecommons.org/licenses/by-nc/4.0/

\section{REFERENCES}

1. Jencks SF, Williams MV, Coleman EA. Rehospitalizations among patients in the Medicare fee-for-service program. $N$ Engl J Med. 2009;360:1418-28.

2. Gheorghiade M, Vaduganathan M, Fonarow GC, et al. Rehospitalization for heart failure: problems and perspectives. J Am Coll Cardiol. 2013;61:391-403.

3. Lloyd-Jones D, Adams RJ, WRITING GROUP MEMBERS. Heart disease and stroke statistics--2010 update: a report from the American Heart Association. Circulation 2010;121:e46-e215.

4. Solomon SD, Dobson J, Pocock S, et al. Influence of nonfatal hospitalization for heart failure on subsequent mortality in patients with chronic heart failure. Circulation. 2007;116:1482-7.

5. Okura Y, Ramadan MM, Ohno Y, et al. Impending epidemic: future projection of heart failure in Japan to the year 2055. Circ J. 2008;72:489-91.

6. Saito M, Negishi K, Marwick TH. Meta-analysis of risks for shortterm readmission in patients with heart failure. Am J Cardiol. 2016;117:626-32.

7. Braunstein JB, Anderson GF, Gerstenblith G, et al. Noncardiac comorbidity increases preventable hospitalizations and mortality among Medicare beneficiaries with chronic heart failure. J Am Coll Cardiol. 2003;42:1226-33.

8. Lang CC, Mancini DM. Non-cardiac comorbidities in chronic heart failure. Heart. 2007;93:665-71.

9. Rushton CA, Satchithananda DK, Jones PW, et al. Noncardiovascular comorbidity, severity and prognosis in non-selected heart failure populations: A systematic review and meta-analysis. Int J Cardiol. 2015;196:98-106.

10. Takahashi K, Saito M, Inaba S, et al. Contribution of the long-term care insurance certificate for predicting 1-year all-cause readmission compared with validated risk scores in elderly patients with heart failure. Open Heart. 2016;3:e000501.

11. Stewart S, Mclntyre K, Capewell S, et al. Heart failure in a cold climate. Seasonal variation in heart failure-related morbidity and mortality. J Am Coll Cardiol. 2002;39:760-6.

12. Milo-Cotter $\mathrm{O}$, Setter I, Uriel $\mathrm{N}$, et al. The daily incidence of acute heart failure is correlated with low minimal night temperature: cold immersion pulmonary edema revisited? J Card Fail. 2006;12:114-9.

13. Qiu H, Yu IT, Tse LA, et al. Is greater temperature change within a day associated with increased emergency hospital admissions for heart failure? Circ Heart Fail. 2013;6:930-5.

14. Krumholz HM, Amatruda J, Smith GL, et al. Randomized trial of an education and support intervention to prevent readmission of patients with heart failure. J Am Coll Cardiol. 2002;39:83-9.

15. Rich MW, Beckham V, Wittenberg C, et al. A multidisciplinary intervention to prevent the readmission of elderly patients with congestive heart failure. N Engl J Med. 1995;333:1190-5.

16. Hersh AM, Masoudi FA, Allen LA. Postdischarge environment following heart failure hospitalization: expanding the view of hospital readmission. J Am Heart Assoc. 2013;2:e000116.

17. Cook NL, Lauer MS. The socio-geography of heart failure: why it matters. Circ Heart Fail. 2011;4:244-5. 
18. McMurray JJ, Adamopoulos S, Anker SD, et al. ESC guidelines for the diagnosis and treatment of acute and chronic heart failure 2012: The Task force for the diagnosis and treatment of acute and chronic heart failure 2012 of the European Society of Cardiology. Developed in collaboration with the Heart Failure Association (HFA) of the ESC. Eur J Heart Fail. 2012;14:803-69.

19. Krumholz HM, Chen YT, Wang Y, et al. Predictors of readmission among elderly survivors of admission with heart failure. Am Heart $J$. 2000;139(1 Pt 1):72-7.

20. Levine BD, Zuckerman JH, deFilippi CR. Effect of high-altitude exposure in the elderly: the tenth mountain division study. Circulation. 1997:96:1224-32.

21. Parati G, Agostoni P, Basnyat B, et al. Clinical recommendations for high altitude exposure of individuals with pre-existing cardiovascular conditions. Eur Heart J 2018;39:1546-54.

22. Bärtsch P, Gibbs JS. Effect of altitude on the heart and the lungs. Circulation. 2007:116:2191-202.
23. Wu JR, Moser DK, Rayens MK, et al. Rurality and event-free survival in patients with heart failure. Heart Lung. 2010;39:512-20.

24. Casper M, Nwaise I, Croft JB, et al. Geographic disparities in heart failure hospitalization rates among Medicare beneficiaries. J Am Coll Cardiol. 2010;55:294-9.

25. Kotb A, Cameron C, Hsieh S, et al. Comparative effectiveness of different forms of telemedicine for individuals with heart failure (HF): a systematic review and network meta-analysis. PLoS One. 2015;10:e0118681.

26. Inglis SC, Clark RA, Dierckx R, et al. Structured telephone support or non-invasive telemonitoring for patients with heart failure. Cochrane Database Syst Rev. 2015;(10):CD007228.

27. Hatano E. Long-term Care Insurance in Japan: How physicians are involved in providing rehabilitation for the elderly. Japan Med Assoc J. 2012;55:231-9. 